\title{
A SOLIDÃO DO UM, NA OBRA “O DIA EM QUE ME TORNEI MULHER"
}

\author{
Danielle Vidal Pessoa ${ }^{1}$ e Paulo Wenderson Teixeira Moraes ${ }^{2}$ \\ ${ }^{1}$ Bolsista PIBIC/FAPESB, Graduanda em Psicologia, Universidade Estadual de Feira de Santana. E-mail: \\ daniellevidal01@hotmail.com \\ ${ }^{2}$ Orientador, Departamento de Ciências Humanas e Filosofia, Universidade Estadual de Feira de Santana. E-mail: \\ pwmoraes@yahoo.com
}

PALAVRAS-CHAVE: Psicanálise, feminino, cinema.

\section{INTRODUÇÃO}

A mulher, no contexto da teoria psicanalítica freudiana, é definida pela via negativa em referência ao falo $(-\varphi)$. Em seus escritos, Freud nos diz que a sexualidade feminina constitui um "continente obscuro" para a psicologia, de tal modo que a mesma não deu por encerrada a questão sobre a sexualidade feminina. A feminilidade é apontada por Freud ([1932-1933] 2008, p. 127) como podendo ser assumida pela via da demanda do falo simbólico ao outro, através da maternidade, ou na relação amorosa com um parceiro em geral seguindo o tipo de relação que tinha com o pai, mas que pode em alguns casos alternar com a hostilidade e ambivalência que caracterizam o vínculo com a mãe no período do complexo de Édipo. Já Lacan (1972-73/1985), em sua extensão da teoria freudiana, ao instaurar o aforismo "A mulher não existe", referindo-se ao fato de que não encontramos uma inscrição no inconsciente para o que é $A$ mulher, assim como encontramos para o que é o homem a partir do falo, Lacan nos dirá que na ordem do saber analítico, o feminino é introduzido como comportando algo da ordem de um desconhecido, do impossível de ser dito, tratando-se, portanto, de um gozo impossível de ser significantizado. Frente a tais considerações, o presente trabalho incita a elaboração de uma discussão acerca das representações da feminilidade nos discursos contemporâneos, identificando possibilidades através das quais os sujeitos femininos se articulam enquanto a construção subjetiva. Para tal, trabalharemos com revisão literária a partir da obra de Freud, Lacan e teóricos contemporâneos, articulando tal conhecimento à produção cinematográfica $O$ dia em que me tornei Mulher (Direção: Marzieh Meshkini Makhmalbaf, Irã, 2000. 78'. Son, Color, Formato:16mm.).

\section{MATERIAIS E MÉTODOS}

Foi realizada pesquisa teórica, desenvolvida nas seguintes etapas: revisão bibliográfica; fichamentos; sistematização e organização da escrita, segundo uma perspectiva hermenêutica criativa (Campos, Coelho Jr., 2010), por tratar-se de uma metodologia que viabiliza uma maior abertura para o exame contingencial das vias de ação do objeto de estudo, sejam os conceitos teóricos clássicos ou suas atualizações clínicas que foram surgindo ao decorrer do período de pesquisa, e a busca do conhecimento através da implicação subjetiva, fazendo uso da teoria psicanalítica. Em conjunto, foi realizada análise de obras cinematográficas: interpretação e exploração dos conteúdos presentes em filmes (AUMONT, 2005). A psicanálise e a arte têm como base-comum a linguagem e, a partir dela, ambas constroem narrativas. Se no cinema a narrativa é provinda da montagem técnica das cenas e sequências, na psicanálise a montagem é obra do próprio sujeito, e é a partir dela, que o indivíduo amarrará suas significações, de modo a construir um novo sentido para suas vivências através da construção de saberes sobre si. No presente material, trabalhamos com o longa metragem $O$ dia em que me tornei Mulher, sendo a análise estruturada sob a discussão da posição subjetiva feminina, a partir do referencial teórico da psicanálise, contextualizando-a com as variadas invenções singulares do que é ser mulher na contemporaneidade. 


\section{ANÁLISE E DISCUSSÃO DOS RESULTADOS}

Em seu último texto sobre "A feminilidade" (1936), Freud comunica que "De acordo com sua natureza peculiar, a psicanálise não tenta descrever o que é a mulher - seria esta uma tarefa difícil de cumprir -, mas se empenha em indagar como é que a mulher se forma, como a mulher se desenvolve desde a criança dotada de disposição bissexual.", visto que desvendar o enigma do feminino era, até então, uma tarefa marcada pelo signo da impossibilidade. Segundo ensinamentos de Lacan (1972-73/1985), ser homem ou mulher é da ordem de um dizer, e não de um saber, de tal modo que a diferença sexual não diz respeito a homens e mulheres anatomicamente falando, sendo que a localização subjetiva independe do sexo biológico, mas que é o desejo, instaurado no processo de sexuação do vir a ser homem ou mulher, que possibilita a construção simbólica - a partir do viés imaginário - de um existir masculino ou feminino. Nesse sentido, o lugar do feminino é entendido a partir da ascensão da castração, como não-toda inscrita na lógica fálica, não se apresentando como um conjunto fechado, impedindo que se constitua uma classe feminina como há no masculino. Então, dizse que as mulheres são únicas e só podem ser contadas uma a uma. Não há $A$ mulher "artigo definido" para designar o universal, visto que não há nela um significante que lhe seja específico (ANTELO, 2012, p. 32), restando a cada uma a construção da sua singularidade. De acordo com a teoria psicanalítica, não há uma definição do que venha a ser o feminino, mas equivalências e a afirmativa de que na impossibilidade de haver uma chave-mestra que decifre o que é uma mulher, elas só podem ser descritas uma a uma. Ser mulher, então, é um processo de inventar-se.

Ao que diz respeito à produção cinematográfica, se concordarmos que o filme abre-se ao campo da significação, a psicanálise torna-se uma ferramenta crucial para situar as posições assumidas pelo feminino no cinema. Exatamente por entendermos que a recepção cinematográfica é passível de várias abordagens que correspondem aos múltiplos pontos de vista de cada expectador (AUMONT, 1995), o cinema - tido como uma arte contemporânea da psicanálise - torna-se relevante enquanto fonte para discussão teórica, a partir do momento em que o modo de endereçamento passa a ser visto como um evento ocorrente entre a coletividade e o subjetivo, sendo, quem sabe, essa a função do audiovisual: apresentar-se como uma ferramenta que não está limitada a si - que não se esgota enquanto espelho da civilização, mas age como questionador da mesma, tendo a competência de levar o indivíduo a se implicar ante a imagem, incitando possíveis remontagens pulsionais.

A condição do feminino na sociedade tem sido um dos principais temas das obras audiovisuais islâmicas a qual países ocidentais têm acesso. O que o filme "O dia em que me tornei mulher" traz como primeiro diferencial é o fato de ser dirigido por uma mulher, dando ao mesmo um caráter auto-reflexivo que tem como questão primeira a representação cinematográfica da mulher iraniana. A diretora Marzieh Meshkini Makhmalbaf, optou por produzir uma película setorizada em três episódios distintos, que ao longo da obra dialogam entre si. Como ponto de partida, as três crônicas partem de acontecimentos cotidianos para a abordagem sistemática de temas que transcorrem a menarca, o matrimônio e o envelhecimento. A marcante presença do véu - trazido no filme enquanto signo opressor e de proteção - é ressaltada no filme, como um eco propulsor da fala que se encontra fadada ao vazio, onde a imagem repetitiva da jangada guiada por este mesmo véu, assume a função precisa de pontuar o sem-limite próprio da sexualidade feminina. Sem-limite este - que comunga com a solidão -, expresso em suas diferentes formas, que põe em evidência a relação singular existente entre o desejo, sinthoma, e gozo.

No primeiro episódio somos apresentados a Hava, uma criança que, no dia do seu nono aniversário, é informada pela avó que havia finalmente se tornado mulher - ela menstruou 
pela primeira vez. A menarca, tida como um dos códigos sociais de inscrita do feminino no real, vem acompanhada da proibição da criança em manter contato com seus amigos do sexo masculino. Assim, tanto o tornar-se mulher quanto a feminilidade exigida a Hava, aparecem inscritas como uma renúncia e um pedido direcionado ao Outro.

Ainda que Freud tenha afirmado que o ser mulher é um tornar-se, e não algo restrito as delimitações biológicas, o conjunto de suas investigações é certeiro ao não ignorar que enquanto indivíduos sociais, somos lidos como sendo homens ou mulheres antes mesmo de nascer. Tal determinação parte da visão de uma mínima diferença inscrita nos corpos - se o feto possui um pênis ou não -, com o qual teremos que nos haver para construir a posição a partir da qual desejamos, e o discurso a partir do qual nos enunciaremos. Hava, segundo moldes da cultura islâmica, passa então a questionar nas entrelinhas dos seus diálogos, o que é ser mulher aos nove anos de idade, onde a obediência seguida da contrariedade pelos dito da mãe, dão sinal do rompimento da identificação ilusória com o seu objeto de desejo, passando para uma identificação ancorada no real, fazendo com que a criança possa, então, se haver com o trinômio falo - fala - falta-a-ser. Tendo amizades majoritariamente do sexo masculino, a criança esboça em seu percurso uma travessia que busca desvelar a sua identificação sexual enquanto mulher. Não encontrando respostas que pontuem a diferença subjetiva que há entre ela, Hansan e os outros meninos.

O segundo episódio é tido como o mais ousado em linguagem, já que foi gravado com a câmera em movimento. A jovem Ahoo participa de um torneio cliclístico pelo litoral com outras mulheres, mas enquanto compete, o seu marido surge lhe impondo o retorno imediato para o lar. Ela recusa, e ao longo da sequência virá seu pai, um jurista, os homens da tribo, e seus irmãos infligindo que a jovem obedeça ao marido. Durante todo o percurso, sua insistência em pedalar sem que mantenha algum elo com estas figuras do masculino ou com as outras mulheres que a acompanham no percurso ciclístico, apenas vociferando o seu querer ao pronunciar "sim, realize" em referência a concordância ao divórcio proposto pelo então marido, nos dá sinal da sua solidão, sendo a mesma ilustrada como um posicionamento da jovem enquanto sujeito, posto que ao entrar no campo da linguagem algo se perdeu - ela se fez desejante, porém, auto-exilada de si. O silêncio de Ahoo, paradoxalmente, torna-se um meio de resistência que permite a mesma penetre na sociedade, agindo enquanto determinante a parir do qual mudanças tiveram a capacidade de acontecer, nos dando sinal da tomada de um lugar do feminino que se posiciona ativamente frente a seu desejo. Ahoo é, então, uma mulher entre tantas outras, e essa solidão apresenta-se tendo como bússola a questão de um exílio para o qual resta inventar uma solução singular.

O último episódio é protagonizado por Hoora, uma mulher na terceira idade que contrata jovens garotos para acompanha-la ao shopping, na intenção de comprar o que durante a vida adulta não pode ter: objetos de sua escolha. Ela peregrina entre lojas e ruas atrás de aparatos materiais que justifiquem todos os seus anos vividos em função do matrimônio. Ao final, instala-se numa praia onde literalmente monta a sua casa, com o objetivo de ao vislumbrar tudo o que foi adquirido, conseguir enxergar o que ainda lhe falta.

De acordo com a teoria lacaniana, a impossibilidade da relação sexual promove nos sujeitos a busca inconsciente de possíveis caminhos para lidar com a impossibilidade de tamponar o furo da ausência de um significante que englobe o feminino, sendo que essa busca se efetiva através de objetos, sejam eles pela via do consumo, das palavras de amor, da profissão ou até da maternidade. Para a nossa personagem, então, o desejo da maternidade apresenta-se como uma rolha capaz de tamponar a ausência de si. Dessa forma, se por um lado uma mulher aponta para o real da falta de significação, por outro, ao se constituir enquanto Outra para si mesma, o seu modo de se haver com o rochedo da falta de significação aponta em alusão a um significante, portando um nome capaz de ancorar o sujeito em uma referência. 


\section{CONSIDERAÇÕES FINAIS}

A partir das considerações elaboradas através da pesquisa teórica e a sua aplicabilidade na análise fílmica, podemos dizer que no referente ao ser mulher, nenhum semblante lhes é apropriado, visto que por estarem sob o signo da falta, a solidão de não se saber unidade é inevitável. O uso do filme "O dia em que me tornei mulher" foi proveitoso por ser uma obra rica em simbologias, metáforas e alegorias, que nos permitiu destacar o processo de constituição da subjetividade de cada mulher presente na obra, em seu vir-a-ser. Assim, corroboramos o que a teoria psicanalítica lacaniana tem publicado a respeito do feminino, afirmando que mais além do que já foi dito sobre $A$ mulher, há sempre algo por dizer. Pensar, então, o feminino, é adentrar num universo não-todo enigmático, em que o singular se faz presente em cada mulher, uma a uma, possibilitando-lhes criação de uma feminilidade possível.

\section{REFERÊNCIAS BIBLIOGRÁFICAS}

AUMONT, J. ; BERGALA, A. A estética do filme. Campinas: Papirus, 2007. $304 \mathrm{p}$.

CAMPOS, E. B. V.; COELHO JR., N. E. Incidências da hermenêutica para a metodologia da pesquisa teórica em psicanálise. Estudos de Psicologia. Campinas, v. 27(2), p. 247-257, 2010, abril - junho.

ANTELO, Marcela. Mulheres de Hoje - Figuras do Feminino no Discurso Analítico. Porto Alegre: Ed. BKR, 2012.

FREUD, Sigmund. Feminilidade. In: Obras Completas, vol.XXII. Rio de Janeiro: Imago, 2008.

Três ensaios sobre a teoria da sexualidade, In: Obras Completas, vol.VII, Rio de Janeiro: Imago Editora, 2008.

Algumas Consequências Psíquicas da Distinção Anatômica Entre os Sexos. In: Obras Completas, vol.XIX, Rio de Janeiro: Imago Editora, 2008.

LACAN J. O Seminário - livro 20: Mais, ainda. Rio de Janeiro: Jorge Zahar Editor, 1985.

. O Seminário - Livro 3: as psicoses. Rio de Janeiro: Jorge Zahar Ed., 1988

$\overline{O \text { dia em }}$ que me tornei Mulher (IRÃ, 2000). Dir. Marzieh Meshkini Makhmalbaf. Filme longa metragem (Irã, 78', 2000). 